\title{
LOCATION BASED SERVICE SEBAGAI PENUNJUK LOKASI HOTEL DI KOTA SEMARANG BERBASIS AUGMENTED REALITY
}

\author{
Indra Permana $^{1)}$, Oky Dwi Nurhayati ${ }^{2)}$, Kurniawan Teguh Martono ${ }^{2)}$ \\ Program Studi Sistem Komputer, Fakultas Teknik, Universitas Diponegoro \\ Jalan Prof. Sudharto, Tembalang, Semarang, Indonesia
}

\begin{abstract}
Abstrak - Semarang dikenal sebagai kota yang unik karena mempunyai destinasi wisata yang dipengaruhi oleh banyaknya etnis yang ada. Selain keunikan pariwisatanya, Kota Semarang juga dapat dipandang sebagai kota bisnis, terbukti dengan menjamurnya tempat usaha seperti restaurant, cafe dan yang paling pesat pertumbuhannya saat ini yaitu hotel. Belakangan ini pertumbuhan hotel di Semarang sudah kian pesat. Hal ini juga berpengaruh kepada para pendatang ataupun wisatawan yang singgah di Kota Semarang. Dari banyaknya jumlah hotel yang ada, bukan tidak mungkin jika para pendatang merasa bingung saat mencari hotel yang sesuai dengan keinginan mereka. Tentunya para pendatang memerlukan aplikasi yang dapat menampilkan lokasi dan informasi lengkap tentang hotel di Kota Semarang.

Untuk dapat mewujudkan gagasan tersebut, maka dilakukan sejumlah metode penelitian antara lain studi literatur, mendefinisikan kebutuhan, pengumpulan data hotel pada Dinas Kebudayaan dan Pariwisata Kota Semarang, perancangan dan implementasi aplikasi, serta melakukan pengujian terhadap aplikasi kepada beberapa orang responden. Aplikasi dirancang dengan tujuan untuk memudahkan pengguna ketika hendak mencari hotel di Kota Semarang.

Hasil dari penelitian ini adalah sebuah channel "SMARTEL" (Semarang Augmented Reality Hotel Location) pada aplikasi Junaio untuk mencari lokasi hotel di Kota Semarang. Basis Augmented Reality dipilih karena sifatnya yang real time saat menampilkan data atau informasi, serta mempunyai tampilan visual yang interaktif. Channel akan menampilkan POI (Point of Interest) atau dalam penelitian kali ini yaitu informasi lokasi hotel, yang didasarkan pada lokasi pengguna saat ini berada, atau dikenal dengan istilah LBS (Location Based Service). Dengan adanya channel ini, pengguna dapat lebih mempersingkat waktu dan lebih mudah dalam menemukan dan menuju ke lokasi hotel yang berada di Kota Semarang. Karena SMARTEL masih dalam bentuk channel, maka harapan untuk penelitian kedepannya adalah dapat dikembangkan dalam bentuk aplikasi android (.apk) agar lebih mudah dalam pendistribusiannya.
\end{abstract}

Kata Kunci: Augmented Reality, Location Based Services (LBS), Junaio, POI

\section{Pendahuluan}

\subsection{Latar Belakang}

Kota Semarang merupakan salah satu kota besar di Indonesia. Kota dengan julukan 'KOTA ATLAS' ini mempunyai penduduk dari berbagai macam etnis mulai dari jawa, tionghoa, melayu dan arab, sehingga tidak heran jika Semarang memiliki beragam kebudayaan daerah. Dari banyaknya etnis yang ada, banyak pula destinasi di Kota Semarang yang timbul seiring berkembangnya kebudayaan etnis-etnis tersebut. Hal ini menjadikan Semarang kota yang unik dan patut untuk dikunjungi.

Selain dari segi pariwisata, Kota Semarang bisa dipandang sebagai kota bisnis dan terbukti dengan menjamurnya bisnis restaurant, cafe, dan hotel. Beberapa tahun belakangan ini pertumbuhan hotel di Kota Semarang sangatlah pesat. Dari banyaknya jumlah hotel yang ada, bukan tidak mungkin jika para pendatang merasa kebingungan saat mencari hotel yang cocok untuk tempat mereka menginap. Pada tugas akhir kali ini penulis ingin mengembangakan fitur pencarian lokasi yang ada pada Google Maps sehingga mencari lokasi hotel menjadi lebih interaktif.

Sekarang ini banyak bermunculan aplikasi Location Based Service pada perangkat mobile yang berguna untuk mengatahui posisi geografis suatu tempat. Beberapa dari aplikasi ini menerapkan teknologi AR misalnya Layar, Wikitude, dan Junaio. Aplikasi-aplikasi tersebut menggunakan pendeteksi lokasi (GPS) pada perangkat mobile untuk mendapatkan informasi mengenai lokasi di sekitar penggunanya dan menampilkan augmented view dengan memanfaatkan kamera. Augmented view yang dibuat biasanya berupa tampilan ikon untuk mewakili setiap objek menarik (disebut Point of Interest/POI) di sekitar lokasi ${ }^{[6]}$.

Berdasarkan uraian diatas dan penelitian yang sudah ada, maka penulis tertarik untuk mengembangkan aplikasi tugas akhir dengan judul "LOCATION BASED SERVICE SEBAGAI PENUNJUK LOKASI HOTEL DI KOTA SEMARANG BERBASIS AUGMENTED REALITY". Dengan adanya aplikasi ini, diharapkan baik masyarakat Kota Semarang maupun pendatang dapat lebih mudah dalam menemukan lokasi hotel di Kota Semarang. 


\subsection{Rumusan Masalah}

Berdasarkan latar belakang masalah yang telah dijelaskan sebelumnya, dapat dibuat suatu rumusan masalah sebagai berikut:

Bagaimana merancang serta mengimplementasikan aplikasi Location Based Service yang dapat menampilkan lokasi hotel di Kota Semarang berbasis augmented reality?

\subsection{Batasan Masalah}

Untuk menghindari pembahasan yang meluas, maka dalam tugas akhir ini dibatasi permasalahan dalam lingkup sebagai berikut:

1. LBS augmented reality dijalankan pada perangkat bergerak dengan sistem operasi Android.

2. Pengembangan LBS augmented reality difokuskan pada pembuatan Channel aplikasi Junaio dan aplikasi pengelola database POI (Point of Interest).

3. Data lokasi hotel hanya yang berada di Kota Semarang serta tercatat pada Dinas Kebudayaan dan Pariwisata Kota Semarang.

4. Titik koordinat lokasi hotel diperoleh melalui metode pencarian dengan aplikasi Google Maps.

\subsection{Tujuan Tugas Akhir}

Tujuan dari tugas akhir ini adalah untuk merancang aplikasi Location Based Service (LBS) yang dapat menampilkan lokasi hotel yang ada di Kota Semarang sebagai media pencarian hotel yang mudah dan interaktif dengan adanya tampilan augmented reality

\section{DASAR TEORI}

\subsection{Augmented Reality}

Augmented reality dapat didefinisikan sebagai penggabungan benda-benda nyata dan maya di lingkungan nyata, berjalan secara interaktif secara real time, dan terdapat integrasi antar benda maya dalam dunia nyata. Interaksi juga dimungkinkan terjadi melalui perangkat-perangkat dengan input tertentu ${ }^{[14]}$. Penjelasan mengenai augmented reality tersebut adalah pengertian secara umum. Augmented reality (AR) secara lebih spesifik didefinisikan sebagai teknologi yang mempunyai karakteristik antara lain sebagai berikut:

- Mengkombinasikan dunia nyata dengan grafis komputer.

- Menyediakan interaksi dengan objek secara real time.

- Melakukan pelacakan objek secara real time.

- Menyediakan pengenalan gambar atau objek.

- Menyediakan konteks atau data real time ${ }^{[3]}$.

\subsection{Location Based Service}

Location Based Service (LBS) adalah salah satu bentuk layanan yang didasarkan pada posisi pelanggan berada di saat ini. Kadangkala, user / pelanggan sendiri tidak mengetahui dimana dia berada. Oleh karena itu sistem yang akan bekerja untuk membantu pelanggan menentukan posisinya saat ini. Selanjutnya setelah posisi tersebut diketahui, data tersebut dapat digunakan untuk memenuhi kebutuhan pelanggan dan memungkinkan pelanggan untuk mengakses segala informasi yang terkait dengan posisinya saat ini melauli GPS.

LBS mensyaratkan adanya komunikasi dua arah serta adanya interaksi. Sebagai contoh, pengguna LBS harus berinteraksi dengan penyedia informasi (service provider) untuk memberi tahu posisi, arah, dan jenis informasi yang dicari. Kemudian penyedia informasi (service provider) akan mengirimkan informasi sesuai dengan jenis yang diinginkan pengguna ${ }^{[9][11]}$.

\subsection{Global Positioning System (GPS)}

GPS (Global Positioning System) adalah sistem radio navigasi dan penentuan posisi menggunakan satelit. Nama formalnya adalah NAVSTAR GPS, kependekan dari NAVigation Satellite Timing and Ranging Global Positioning System. Sistem yang dapat digunakan oleh banyak orang sekaligus dalam segala cuaca ini, didesain untuk memberikan informasi posisi dan kecepatan tiga dimensi yang teliti, dan juga informasi mengenai waktu secara kontinyu di seluruh dunia.

Dibandingakan dengan sistem dan metode penentuan posisi lainnya, GPS mempunyai banyak kelebihan dan menawarkan lebih banyak keuntungan, baik dalam segi operasionalisasinya maupun kualitas posisi yang diberikan. Berikut beberapa kelebihan penggunaan GPS:

1. GPS dapat digunakan setiap saat tanpa bergantung pada waktu dan cuaca.

2. GPS mempunyai ketinggian orbit yang cukup tinggi, yaitu sekitar $20.000 \mathrm{~km}$ diatas permukaan bumi dan jumlahnya relatif banyak.

3. Penggunaan GPS dalam penentuan posisi relatif tidak terpengaruh dari topografis daerah survai dibandingkan dengan metode konvensional seperti pengukuran poligon.

4. GPS dapat memberikan ketelitian posisi yang spektrumnya cukup luas.

5. Pemakaian GPS tidak dikenakan biaya oleh pihak pemilik satelit ${ }^{[1]}$.

\subsection{Location Based Service Berbasis AR}

Sebelumnya telah dijelaskan pengertian LBS dan AR. Pada penelitian kali ini penulis akan membuat sebuah aplikasi yang menggabungkan keduanya. Aplikasi ini menerapkan location-based AR seperti misalnya Layar, Wikitude, dan Junaio. Aplikasi-aplikasi tersebut menggunakan sensor lokasi (GPS) pada perangkat mobile untuk mendapatkan informasi mengenai lokasi di sekitar penggunanya dan menampilkan augmented view dengan memanfaatkan kamera. Augmented view yang dibuat biasanya berupa tampilan ikon untuk mewakili setiap objek menarik yang disebut dengan Point of Interest (POI) di sekitar lokasi ${ }^{[9]}$.

\subsection{Junaio}

Junaio merupakan aplikasi dari Metaio. Junaio dirilis pada akhir tahun 2009, tetapi tidak seperti Layar dan Wikitude, Junaio tidak dirilis sebagai AR browser. Junaio dirilis sebagai browser jejaring sosial AR pertama di 
dunia. Versi asli dari junaio berfokus agar memungkinkan pengguna untuk mengirim objek 3D ke dunia maya, dan pengguna lain bisa menggunakan $3 D$ scenes untuk menciptakan scene mereka sendiri untuk berbagi dengan teman.

Metaio menggunakan istilah "channel" untuk menyebut informasi yang ditampilkan dalam sistem augmented reality. Channel tersebut berisi sekumpulan POI, dan dapat dilihat melalui aplikasi Junaio. Pembuatan channel dapat dilakukan melalui website my.metaio.com.

\section{Perancangan Sistem}

Untuk menyelesaikan tugas akhir ini, digunakan metode pengembangan sistem waterfall. Inti dari metode waterfall adalah pengerjaan dari suatu sistem dilakukan secara berurutan atau secara linear. Jadi jika langkah satu belum dikerjakan, maka tidak akan dapat melakukan pengerjaan langkah 2, 3 dan selanjutnya. Secara otomatis tahapan ke-3 akan dapat dilakukan jika tahap ke-1 dan ke2 telah dilakukan. Metode waterfall dipilih karena dapat menghasilkan kualitas sistem yang baik sebab pelaksanaannya dilakukan secara terstruktur dan terawasi.

Pada tahap desain, ada tiga metode yang digunakan yaitu use case diagram, flow chart dan perancangan antarmuka. Proses desain akan menterjemahkan kebutuhan dari perangkat lunak yang sudah dijelaskan sebelumnya

\subsection{Diagram Use Case}

Pada tugas akhir ini, use case digunakan untuk menjelaskan apa saja yang dapat user lakukan terhadap channel SMARTEL (Semarang Augmented Reeality Hotel Location) pada aplikasi Junaio. Gambar 1 menunjukkan use case digaram dari channel SMARTEL.

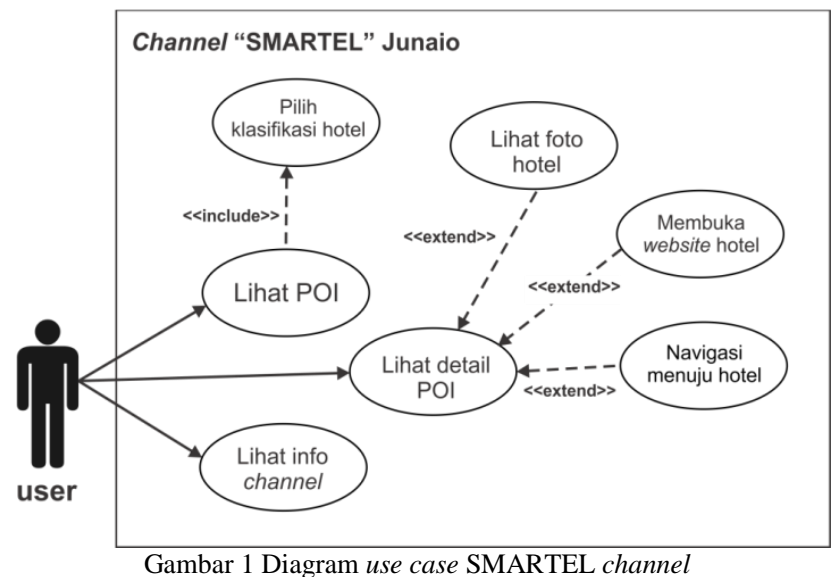

Dari diagram use case tersebut, fungsi atau tugas dapat dijelaskan dengan definisi use case. Definisi Use Case berfungsi sebagai penjelasan mengenai proses yang terdapat pada setiap use case. Tabel 1 menunjukkan definisi use case yang dibuat pada tugas akhir ini.
Tabel 1 Tabel deifinisi use case.

\begin{tabular}{|c|c|c|}
\hline No & $\begin{array}{c}\text { Nama } \\
\text { Use Case }\end{array}$ & Deskripsi \\
\hline UC-01 & Lihat POI & $\begin{array}{l}\text { Fungsionalitas yang dapat } \\
\text { menampilkan informasi nama } \\
\text { hotel di Kota Pekalongan } \\
\text { melalui antarmuka augmented } \\
\text { reality. }\end{array}$ \\
\hline UC-02 & $\begin{array}{c}\text { Lihat } \\
\text { detail POI }\end{array}$ & $\begin{array}{l}\text { Fungsionalitas yang dapat } \\
\text { menampilkan halaman yang } \\
\text { berisi informasi detail hotel } \\
\text { seperti klasifikasi, alamat dan } \\
\text { nomor telfon. }\end{array}$ \\
\hline UC-03 & $\begin{array}{c}\text { Lihat info } \\
\text { channel }\end{array}$ & $\begin{array}{lr}\text { Fungsionalitas } & \text { yang } \\
\text { menampilkan jendela popup } \\
\text { berisi info seputar channel } \\
\text { SMARTEL. }\end{array}$ \\
\hline UC-04 & $\begin{array}{l}\text { Pilih } \\
\text { klasifikasi } \\
\text { hotel }\end{array}$ & $\begin{array}{l}\text { Fungsionalitas berupa tombol } 1 \\
\text { sampai } 5 \text { yang memungkinkan } \\
\text { pengguna menampilkan POI } \\
\text { hotel sesuai dengan tombol } \\
\text { klasifikasi yang dipilih. }\end{array}$ \\
\hline UC-05 & $\begin{array}{c}\text { Lihat foto } \\
\text { hotel }\end{array}$ & $\begin{array}{l}\text { Fungsionalitas untuk } \\
\text { menampilkan foto hotel yang } \\
\text { dipilih. }\end{array}$ \\
\hline UC-06 & $\begin{array}{l}\text { Membuka } \\
\text { website } \\
\text { hotel }\end{array}$ & $\begin{array}{l}\text { Fungsionalitas untuk } \\
\text { mengakses website hotel yang } \\
\text { dipilih. }\end{array}$ \\
\hline UC-07 & $\begin{array}{l}\text { Navigasi } \\
\text { menuju } \\
\text { hotel }\end{array}$ & $\begin{array}{l}\text { Fungsionalitas untuk } \\
\text { mendeteksi lokasi pengguna } \\
\text { saat ini berada dan } \\
\text { menunjukkan rute ke arah hotel } \\
\text { yang dipilih. }\end{array}$ \\
\hline
\end{tabular}

\subsection{Flow Chart}

Desain pengembangan aplikasi salah satunya akan dijelaskan melalui diagram alir atau flow chart. Flow chart pada penelitian ini digunakan untuk menjelaskan urutan proses kerja dari aplikasi pengelolaan data POI untuk channel SMARTEL. Gambar 2 sampai dengan Gambar 4 menunjukkan diagram alir proses pada aplikasi pengelolaan POI berbasis web.

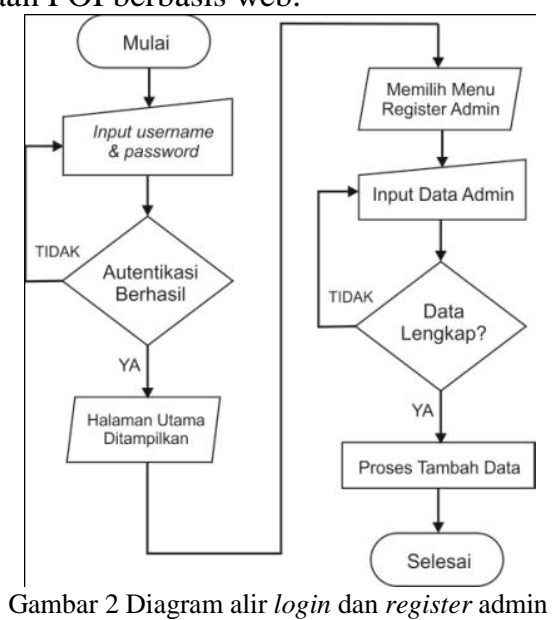

Gambar 2 Diagram alir login dan register admin 


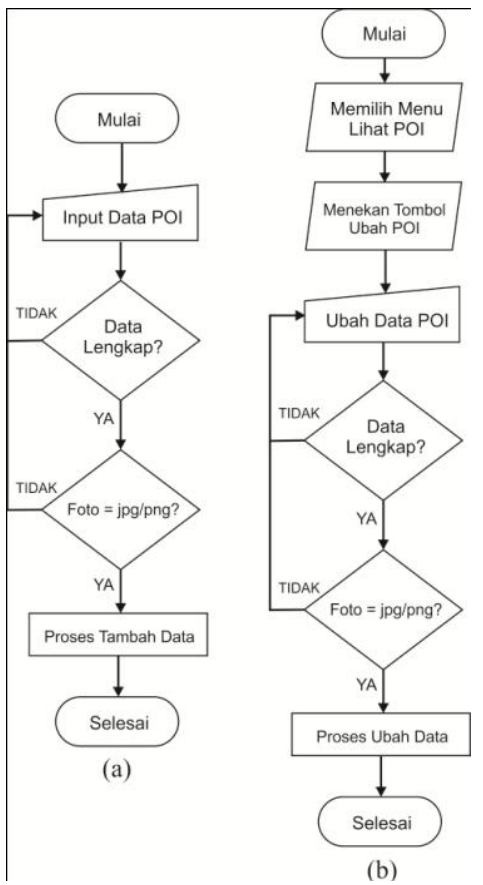

Gambar 3 (a) Diagram alir tambah data. (b) Diagram alir ubah data

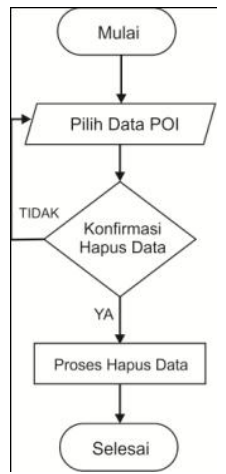

Gambar 4 Diagram alir proses hapus data POI

\subsection{Perancangan Antarmuka}

Desain layout antarmuka merupakan rencana atau gambaran awal seperti apa bentuk tampilan yang nantinya akan dibuat, dalam hal ini adalah antarmuka channel dan antarmuka aplikasi pengelola POI berbasis web. Dimulai dari Gambar 5 dan Gambar 6 yang menunjukkan rancangan antarmuka tampilan utama channel SMARTEL.

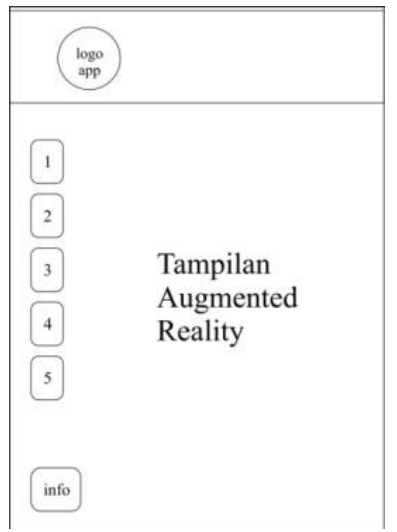

Gambar 5 Perancangan antarmuka halaman awal channel

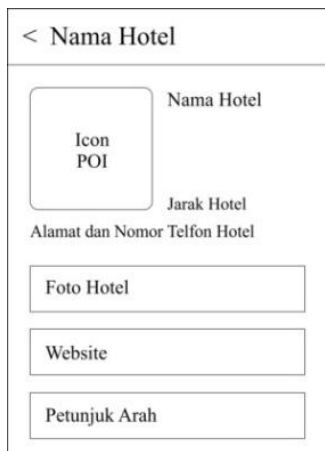

Gambar 6 Perancangan antarmuka halaman detail POI

Gambar 7 dan Gambar 8 menunjukkan perancangan antarmuka untuk aplikasi pengelolaan POI berbasis web.

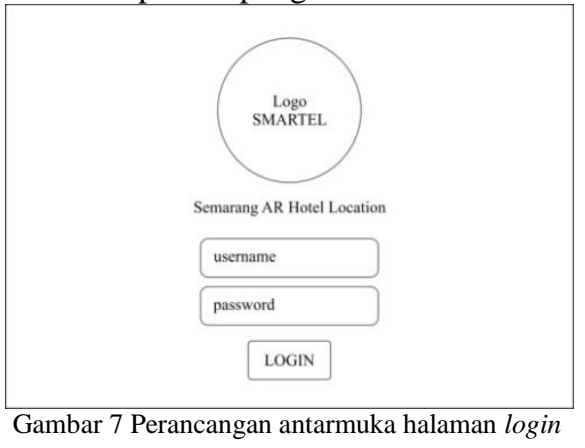

Daftar POI Tambah POI Tambah Admin Publish $\checkmark$ Username Admin $~$

Daftar POI Hotel di Kota Semarang

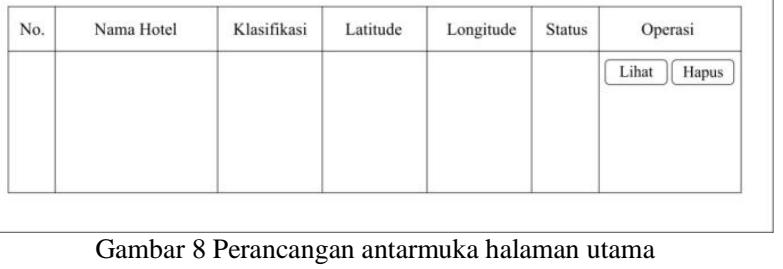

\subsection{Perancangan Basis Data}

Pembuatan basis data dilakukan melalui localhost/phpmyadmin yang nantinya tabel akan diunggah kedalam web hosting. Penyimpanan data akan melibatkan dua buah tabel, yaitu tabel poi untuk menyimpan data hotel dan tabel admin untuk menyimpan data admin. Struktur tabel poi pada basis data terdiri atas kolomkolom seperti pada Tabel 2.

Tabel 2 Struktur tabel poi.
\begin{tabular}{|c|l|l|}
\hline No. & Nama Kolom & Tipe Data \\
\hline 1 & Id & Int $(4)$ \\
\hline 2 & latitude & Decimal $(10,8)$ \\
\hline 3 & longitude & Decimal $(11,8)$ \\
\hline 4 & nama_hotel & Varchar $(50)$ \\
\hline 5 & bintang & Int $(2)$ \\
\hline 6 & Site & Varchar $(70)$ \\
\hline 7 & Detail & Text \\
\hline 8 & Foto & Text \\
\hline 9 & Status & Varchar $(10)$ \\
\hline
\end{tabular}


Tabel 3 menunjukkan struktur dari tabel admin. Tabel 3 Struktur tabel admin.

\begin{tabular}{|c|l|l|}
\hline No. & Nama Kolom & Tipe Data \\
\hline 1 & $\underline{\text { id}}$ & Int (3) \\
\hline 2 & user & Varchar (25) \\
\hline 3 & pass & Varchar (32) \\
\hline 4 & nama & Varchar (25) \\
\hline 5 & alamat & Text \\
\hline 6 & no_hp & Varchar (15) \\
\hline
\end{tabular}

\section{IMPLEMENTASI DAN PENGUJIAN}

\subsection{Implementasi}

\subsubsection{Pembuatan Antarmuka Pengelolaan POI}

Peracangan layout antarmuka aplikasi sudah dilakukan pada bab sebelumnya, dan sekarang masuk kedalam tahap implementasi. Antarmuka yang dimaksud adalah aplikasi pada sisi server dengan menggunakan filefile PHP. Jadi file-file PHP yang sudah jadi akan diunggah ke web hosting sama seperti database, sehingga admin dapat mengelola POI kapanpun dan dimanapun berada secara online. Berikut adalah antarmuka dari aplikasi yang telah dibuat sesuai dengan yang sudah dirancang sebelumnya seperti yang ditunjukkan pada Gambar 9 dan Gambar 10 untuk aplikasi pengelolaan POI.
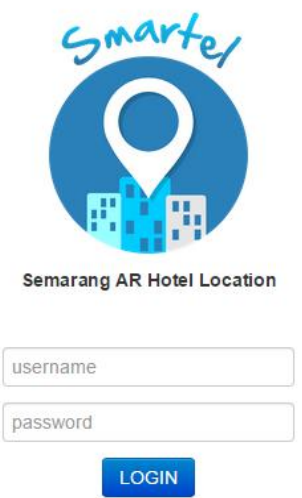

Gambar 9 Tampilan halaman login aplikasi

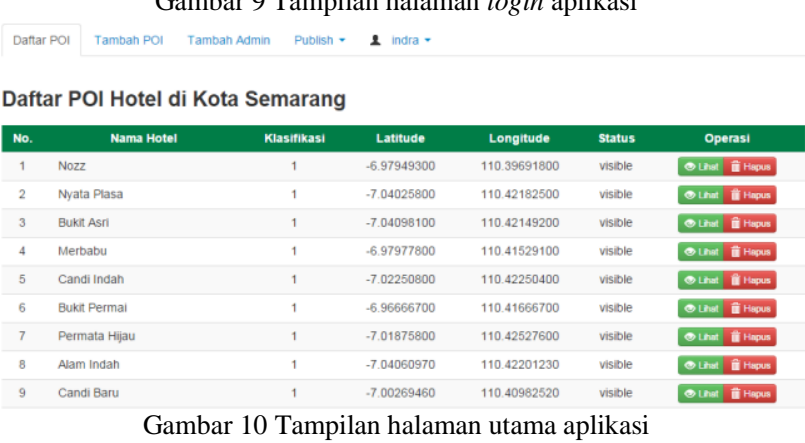

\subsubsection{Pembuatan File XML Penampil POI}

Pada dasarnya channel dari metaio akan mengakses file XML yang berisikan data POI untuk ditampilkan dalam sistem AR. Pada penelitian kali ini digunakan teknik mengambil data dari database MySQL dan diubah kedalam bentuk XML (parsing MySQL to XML). Jadi nantinya ada sebuah file PHP yang berfungsi untuk melakukan tugas parsing tersebut. File XML terdiri atas beberapa tag yang menyimpan informasi lengkap dari POI hotel seperti nama hotel, alamat, klasifikasi hotel, koordinat hotel, nomor telfon, alamat website, dan foto hotel. File XML akan diunggah ke web hosting agar dapat diakses oleh channel secara online. Berikut adalah potongan isi dari file XML yang digunakan. Satu tag <object> mewakili informasi satu POI.

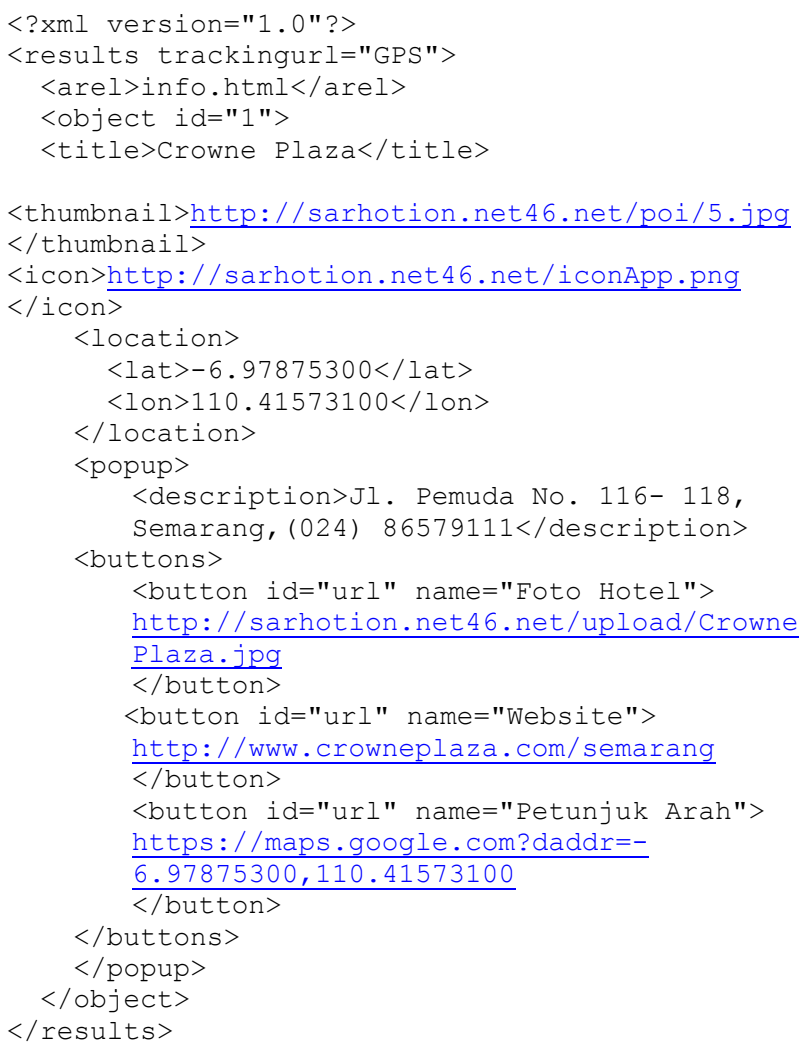

\subsubsection{Pembuatan Channel POI}

Pembuatan chanel dilakukan lewat website khusus untuk pengembang dari Metaio, yaitu my.metaio.com. Pada penelitian ini diibaratkan Junaio adalah televisi, sedangkan yang akan dibuat adalah channel nya. Jadi nantinya Junaio akan mengakses channel yang berisi informasi POI, dan ditampilkan dalam sistem AR. Informasi POI pada channel bersumber dari 5 file XML yang telah dibuat sebelumnya. Langkah-langkahnya sebagai berikut:

1. Mendaftar sebagai developer pada laman Metaio.

2. Ketika proses pendaftaran sudah berhasil, maka akan tampil halaman utama Metaio developer portal. Pembuatan channel dapat dilakukan pada menu $M y$ Channels kemudian memilih Create a new channel seperti pada Gambar 11 dan Gambar 12.

3. Setelah pembuatan kelima channel selesai, maka channel hotel bintang 1 akan dijadikan sebagai default channel. Jadi begitu user mengakses channel SMARTEL, maka yang pertama ditampilkan adalah POI hotel bintang 1. 

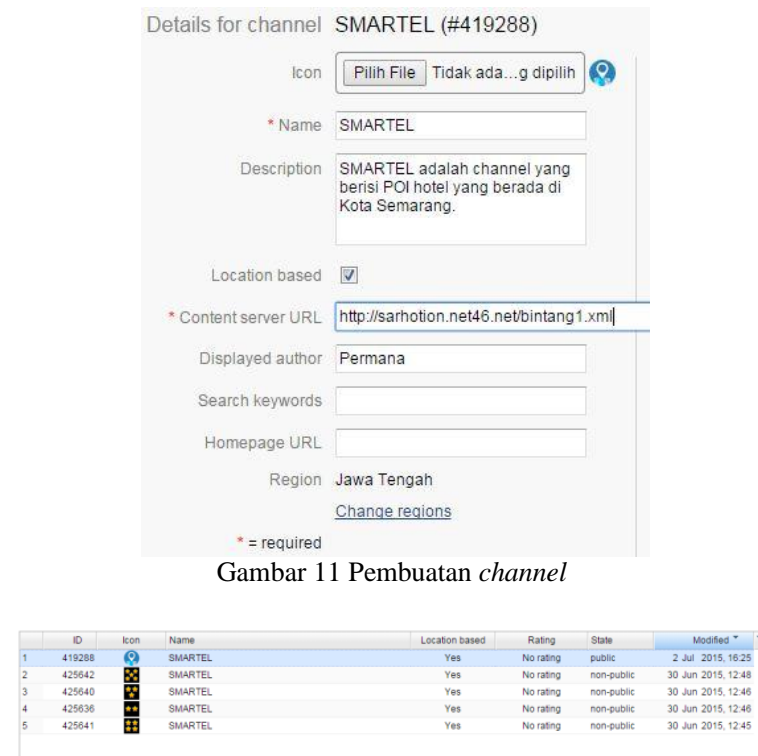

Gambar 12 Kelima channel sudah dibuat

\subsection{Pengujian}

\subsubsection{Pengujian Black Box}

Pengujian LBS AR Hotel di Kota Semarang yang telah dibuat, dilakukan dengan menggunakan metode black box. Pengujian black box merupakan tahapan pengujian yang dilakukan untuk memeriksa fungsi-fungsi yang terdapat pada aplikasi, apakah hasilnya sudah sesuai yang diinginkan. Pengujian ini juga dilakukan untuk mengetahui apakah masih terdapat error pada perangkat lunak. Pengujian dilakukan terhadap aplikasi pengelolaan POI yang berada pada sisi server dan channel SMARTEL yang berada pada sisi pengguna. Tabel pengujian aplikasi pengelolaan POI dan tabel pengujian channel SMARTEL terdapat pada halaman lampiran.

Berdasarkan hasil pengujian fungsional atau pengujian black box, untuk aplikasi pengelolaan POI sudah dapat melakukan koreksi kesalahan saat input data, menambah, mengubah dan menghapus data, semua fungsi dan tombol sudah bekerja dengan baik. Jadi dapat ditarik kesimpulan bahwa perangkat lunak pengelola POI pada server tidak memiliki kesalahan secara fungsional dan mengeluarkan hasil yang sesuai dengan yang diharapkan. Pengujian selanjutnya dilakukan terhadap channel SMARTEL seperti pada Gambar 13 dan Gambar 14.

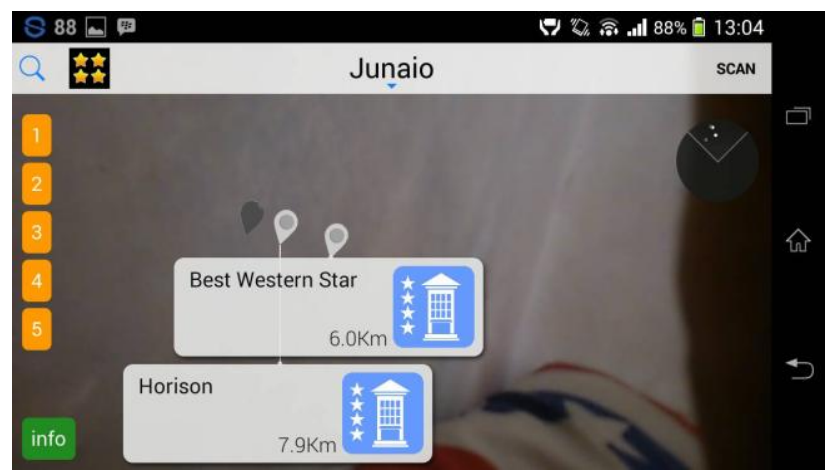

Gambar 13 Tampilan halaman utama channel

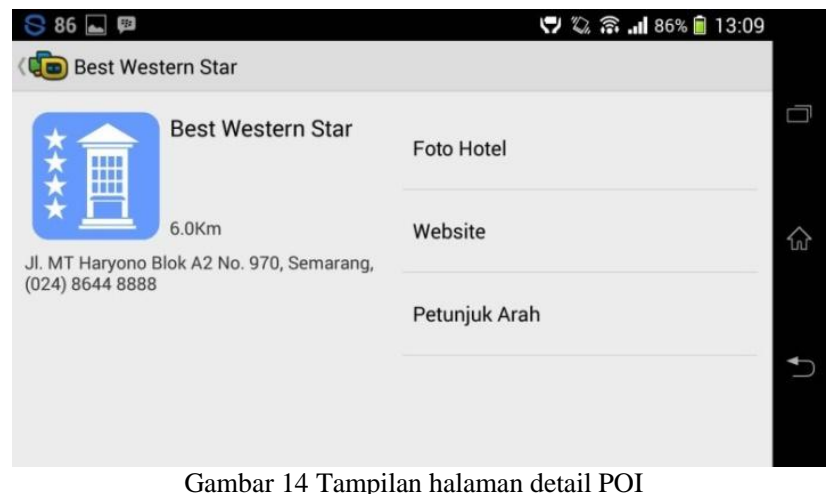

Gambar 14 Tampilan halaman detail POI

Untuk hasil pengujian dari channel SMARTEL juga didapati semua tombol berfungsi dengan baik, pindah channel juga berjalan lancar dan sistem dapat menampilkan informasi yang diambil dari data dari database. Maka dapat dipastikan bahwa channel SMARTEL tidak memiliki kesalahan secara fungsional dan mengeluarkan hasil sesuai dengan yang diharapkan.

\subsubsection{Pengujian Usability}

Pengujian usability merupakan pengujian yang melibatkan responden dengan tujuan untuk mengetahui sejauh mana kualitas sistem dari segi penggunaan, apakah sudah memenuhi harapan atau belum. Pengujian usability dilakukan terhadap channel SMARTEL karena berada pada sisi pengguna. Untuk itu dalam pengujian usabilitas dilakukan survei terhadap responden Jumlah pengguna yang berperan dalam pengujian adalah 15 responden. Kuesioner terdiri atas 10 pernyataan seperti yang dan menggunakan skala Likert dengan pilihan jawaban sangat setuju, setuju, tidak setuju, dan sangat tidak setuju. Tabel 4 menunjukkan pilihan jawaban dan nilai (bobot) masingmasing jawaban.

Tabel 4 Pilihan jawaban skala Likert.
\begin{tabular}{|c|c|}
\hline Nilai & Keterangan \\
\hline 4 & Sangat setuju \\
\hline 3 & Setuju \\
\hline 2 & Tidak setuju \\
\hline 1 & Sangat tidak setuju \\
\hline
\end{tabular}

Menurut Jacob Nielsen ${ }^{[4]}$, aspek-aspek dalam usability testing harus mencakup hal-hal sebagai berikut:

a. Learnability, menjelaskan tingkat kemudahan pengguna atau user untuk menyelesaikan task dasar ketika pertama kali mereka berhadapan dengan sistem yang ada.

b. Efficiency, menjelaskan seberapa cepat pengguna dapat menyelesaikan tugas-tugas yang ada saat mereka pertama kali mempelajari sistem tersebut.

c. Memorability, merupakan kemampuan sistem untuk mudah diingat, baik dari sisi fitur, menu yang ada, maupun cara pengoperasiannya.

d. Errors, menjelaskan kemungkinan terjadinya error atau kesalahan yang dilakukan oleh pengguna terhadap sistem.

e. Satisfaction, menjelaskan tentang tingkat kepuasan pengguna dalam menggunakan sistem yang telah dibuat. 
Hasil perancangan 10 pertanyaan kuisioner yang mengacu pada kelima aspek tersebut dapat dilihat pada Tabel 5.

Keterangan tabel:

- L : mewakili learnability

- E : mewakili efficiency

- M : mewakili memorability

- Er : mewakili errors

- S : mewakili satisfaction

Tabel 5 Rancangan pertanyaan kuesioner berdasarkan aspek usability.

\begin{tabular}{|c|c|c|c|c|c|c|}
\hline \multirow{2}{*}{ No } & \multirow{2}{*}{ Pernyataan } & \multicolumn{5}{|c|}{ Aspek Usability } \\
\hline & & $\mathbf{L}$ & $\mathbf{E}$ & M & Er & $\mathbf{S}$ \\
\hline 1 & $\begin{array}{l}\text { Menu pada tampilan } \\
\text { awal mudah dikenali }\end{array}$ & & & & & \\
\hline 2 & $\begin{array}{l}\text { Pengguna dapat lebih } \\
\text { mudah menemukan } \\
\text { lokasi hotel dengan } \\
\text { aplikasi yang telah } \\
\text { dibuat. }\end{array}$ & & & & & \\
\hline 3 & $\begin{array}{l}\text { Aplikasi cukup interaktif } \\
\text { karena menampilkan } \\
\text { lokasi hotel dengan } \\
\text { teknologi augmented } \\
\text { reality dan dengan radar. }\end{array}$ & & & & & \\
\hline 4 & $\begin{array}{l}\text { Informasi detail setiap } \\
\text { hotel ditampilkan dengan } \\
\text { baik. }\end{array}$ & & & & & \\
\hline 5 & $\begin{array}{l}\text { Pengguna dapat } \\
\text { memahami fungsi dari } \\
\text { setiap menu yang } \\
\text { muncul. }\end{array}$ & & & & & \\
\hline 6 & $\begin{array}{l}\text { Semua tombol berfungsi } \\
\text { dengan baik }\end{array}$ & & & & & \\
\hline 7 & $\begin{array}{l}\text { Pengguna terbantu } \\
\text { dengan adanya petunjuk } \\
\text { arah menuju ke tempat } \\
\text { hotel berada }\end{array}$ & & & & & \\
\hline 8 & $\begin{array}{l}\text { Pengguna dapat } \\
\text { mengakses setiap } \\
\text { channel dengan baik dari } \\
\text { setiap menu angka yang } \\
\text { ditekan }\end{array}$ & & & & & \\
\hline 9 & $\begin{array}{l}\text { Pengguna dapat } \\
\text { mengingat kembali } \\
\text { fungsi dari setiap tombol } \\
\text { yang pernah digunakan }\end{array}$ & & & & & \\
\hline 10 & $\begin{array}{l}\text { Pengguna merasa } \\
\text { nyaman ketika } \\
\text { menggunakan aplikasi }\end{array}$ & & & & & \\
\hline
\end{tabular}

Agar hasil perhitungan dapat diterjemahan kembali menjadi hasil skala jawaban maka diperlukan kriteria interpretasi sebagai berikut:

$-0-25 \%=$ Sangat tidak setuju

- $26-50 \%=$ Kurang setuju

$-51-75 \%=$ Setuju

- $76-100 \%=$ Sangat Setuju
Tabel 6 menunjukkan persentase hasil perhitungan dari jawaban setiap pertanyaan pada kuesioner yang diberikan kepada responden, dengan menggunakan persamaan sebagai berikut.

$$
H=\frac{Z}{J} x 100 \%
$$

Keterangan:

$\mathrm{H}=$ Hasil perhitungan

$\mathrm{Z}=$ Jumlah skor total jawaban

$\mathbf{J}=$ Skor tertinggi dikalikan dengan jumlah responden (Skor ideal)

Tabel 6 Hasil perhitugan skala Likert channel SMARTEL.

\begin{tabular}{|c|c|c|c|}
\hline No & Pernyataan & Nilai H & Kategori \\
\hline 1 & $\begin{array}{l}\text { Menu pada tampilan awal } \\
\text { mudah dikenali }\end{array}$ & $75 \%$ & Setuju \\
\hline 2 & $\begin{array}{l}\text { Pengguna dapat lebih } \\
\text { mudah menemukan lokasi } \\
\text { hotel dengan aplikasi yang } \\
\text { telah dibuat. }\end{array}$ & $88,33 \%$ & $\begin{array}{l}\text { Sangat } \\
\text { Setuju }\end{array}$ \\
\hline 3 & $\begin{array}{l}\text { Aplikasi cukup interaktif } \\
\text { karena menampilkan } \\
\text { lokasi hotel dengan } \\
\text { teknologi augmented } \\
\text { reality dan dengan radar. }\end{array}$ & $88,33 \%$ & $\begin{array}{l}\text { Sangat } \\
\text { Setuju }\end{array}$ \\
\hline 4 & $\begin{array}{l}\text { Informasi detail setiap } \\
\text { hotel ditampilkan dengan } \\
\text { baik. }\end{array}$ & $73,33 \%$ & Setuju \\
\hline 5 & $\begin{array}{l}\text { Pengguna dapat } \\
\text { memahami fungsi dari } \\
\text { setiap menu yang muncul. }\end{array}$ & $68,33 \%$ & Setuju \\
\hline 6 & $\begin{array}{l}\text { Semua tombol berfungsi } \\
\text { dengan baik }\end{array}$ & $83,33 \%$ & $\begin{array}{l}\text { Sangat } \\
\text { Setuju }\end{array}$ \\
\hline 7 & $\begin{array}{l}\text { Pengguna terbantu dengan } \\
\text { adanya petunjuk arah } \\
\text { menuju ke tempat hotel } \\
\text { berada }\end{array}$ & $91,66 \%$ & $\begin{array}{l}\text { Sangat } \\
\text { Setuju }\end{array}$ \\
\hline 8 & $\begin{array}{l}\text { Pengguna dapat } \\
\text { mengakses setiap channel } \\
\text { dengan baik dari setiap } \\
\text { menu angka yang ditekan }\end{array}$ & $81,66 \%$ & $\begin{array}{l}\text { Sangat } \\
\text { Setuju }\end{array}$ \\
\hline 9 & $\begin{array}{l}\text { Pengguna dapat } \\
\text { mengingat kembali fungsi } \\
\text { dari setiap tombol yang } \\
\text { pernah digunakan }\end{array}$ & $86,66 \%$ & $\begin{array}{l}\text { Sangat } \\
\text { Setuju }\end{array}$ \\
\hline 10 & $\begin{array}{l}\text { Pengguna merasa nyaman } \\
\text { ketika menggunakan } \\
\text { aplikasi }\end{array}$ & $78,33 \%$ & $\begin{array}{l}\text { Sangat } \\
\text { Setuju }\end{array}$ \\
\hline
\end{tabular}

Berdasarkan hasil pengujian usability didapatkan hasil hasil bahwa aplikasi sudah memenuhi kriteria antara lain memudahkan pengguna dalam pencarian lokasi hotel, interaktif dalam menujukkan lokasi hotel, penggunaannya mudah, dan informasi hotel ditampilkan dengan baik. Hal tersebut dibuktikan oleh jawaban dari 15 responden yang jika dirata-rata sebagian besar menyatakan sangat setuju untuk setiap pernyataan yang ada. 


\subsection{Kesimpulan}

\section{Penutup}

Berdasarkan hasil analisis dan pengujian aplikasi Location Based Service sebagai penunjuk lokasi hotel di Kota Semarang berbasis Augmented Reality dapat diambil kesimpulan sebagai berikut:

1. Aplikasi LBS AR sebagai penunjuk lokasi hotel di Kota Semarang ini dikembangkan dengan menggunakan channel dari aplikasi Junaio.

2. Perancangan aplikasi melibatkan web hosting yang berperan sebagai server.

3. Channel menampilkan informasi hotel dari database server yang dapat dikelola oleh admin melalui aplikasi pengelola POI.

4. Teknologi penunjuk lokasi berbasis AR dipilih karena sifatnya yang interaktif, artinya terjadi interaksi 2 arah antara pengguna dengan sistem.

5. Hasil pengujian menunjukkan bahwa perangkat lunak mudah dan interaktif untuk digunakan walaupun untuk orang awam sekalipun.

6. Menu Petunjuk Arah pada masing-masing POI bertujuan mempermudah pengguna dalam mencapai lokasi hotel karena ditampilkannya rute mana yang harus dilalui.

7. Untuk mendapatkan informasi jarak dalam satuan kilometer $(\mathrm{Km})$, sistem perangkat android pengguna harus diatur dalam bahasa Indonesia agar penggunaannya lebih mudah.

8. Channel SMARTEL akan selalu menampilkan informasi hotel terbaru karena file XML yang berada pada web hosting akan selalu diperbarui oleh admin.

9. Pengelolaan POI pada database sever bisa berlangsung cepat terutama ketika ada banyak perubahan terjadi, karena admin yang berwenang mengelola POI bisa lebih dari satu orang.

\subsection{Saran}

Berdasarkan pengujian dan analisa terhadap perangkat lunak yang telah dibuat pada tugas akhir ini, sistem masih memerlukan penyempurnaan, karena itu diberikan beberapa saran sebagai berikut:

1. Pengujian agar dilakukan pada perangkat selain Android, misalnya iOS dan Windows Phone agar mengetahui ada atau tidaknya batasan-batasan jalannya aplikasi pada sistem operasi lain.

2. Aplikasi LBS AR sebagai penunjuk lokasi hotel di Kota Semarang baiknya dibuat dalam bentuk .apk untuk mempermudah publikasinya.

\section{DAFTAR PUSTAKA}

[1] Abidin, H.Z., Penentuan Posisi dengan GPS dan Aplikasiny, Pradnya Paramita, Jakarta, 2000.

[2] Kurniawan, D., "Aplikasi Peta Digital Lokasi Wisata Di Kota Semarang Berbasis Android", Universitas Dianuswantoro, Semarang, 2013.

[3] Madden, L., "Professional Augmented Reality Browsers for Smartphones Programming for Junaio, Layar, and Wikitude”, Wiley Publishing, Inc., United Kingdom, 2011
[4] Nielsen, J., Usability 101: Introduction to Usability, http://www.nngroup.com/articles/usability-101-introduction-tousability/, 14 Agustus 2015

[5] Nugraha, I.S., "Pemanfaatan Augmented Reality untuk Pembelajaran Pengenalan Alat Musik Piano", Teknik Sistem Komputer Universitas Diponegoro, Semarang, 2014.

[6] Prima, P. Dan Gambetta, W., "Penerapan Augmented Reality Berbasis Lokasi dalam Mobile Virtual Tour", Teknik Informatika Institut Teknologi Bandung. Bandung, 2012.

[7] Rizki, Y., "Markerless Augmented Reality pada Perangkat Android", Teknik Elektro Institut Teknologi Sepuluh Nopember, Surabaya, 2012.

[8] S, Steiniger., M, Neun., A, Edwardes., Foundations of Location Based Services, Lecture Notes on LBS, 2006.

[9] Satoto, B.D. dan Rahmanita, E., "Integrasi Augmented Reality pada Mobile Virtual Tour Berbasis Android untuk Pencarian Lokasi dan Rute Terdekat", Program Studi Teknik Informatika Universitas Trunojoyo, Madura, 2013.

[10] Sekaran, Uma.,MetodePenelitianBisnis, Jakarta : SalembaEmpat, 2006.

[11] Setyawan, B., Location Based Service Berbasis Augmented Reality untuk Perangkat Bergerak sebagai Penunjuk Lokasi Wisata dan Belanja Batik di Kota Pekalongan, Skripsi S1, Teknik Sistem Komputer Universitas Diponegoro, Semarang, 2014.

[12] Siltanen, S., Theory and Application of Marker-Based Augmented Reality, VTT Science, Finland, 2012.

[13] Sood, R., Pro Android Augmented Rality, Apress, New York, 2012.

[14] Sutrisno, E.P.A., "Program Aplikasi GPS dan GIS untuk Mencari Lokasi dan Jarak Spbu di Tangerang Selatan dengan Peta dan Augmented Reality Camera-View pada Perangkat Bergerak Berbasis Android", Jurusan Teknik Informatika Universitas Gunadarma, 2011. 


\section{LAMPIRAN MAKALAH}

Tabel 1 Tabel pengujian black box aplikasi pengelolaan POI

\begin{tabular}{|c|c|c|c|}
\hline $\begin{array}{c}\text { Nama } \\
\text { Pengujian }\end{array}$ & Bentuk Pengujian & Hasil yang Diharapkan & Hasil Pengujian \\
\hline \multirow{3}{*}{ Login } & $\begin{array}{l}\text { Mengakses subdomain } \\
\text { sarhotion.net46.net }\end{array}$ & Tampil halaman login & Berhasil \\
\hline & \multirow[t]{2}{*}{ Menekan tombol LOGIN } & $\begin{array}{l}\text { Tampil peringatan saat terjadi kesalahan input } \\
\text { data }\end{array}$ & Berhasil \\
\hline & & Tampil halaman utama ketika masukan benar & Berhasil \\
\hline \multirow{6}{*}{ Tambah POI } & $\begin{array}{l}\text { Memilih menu Tambah POI } \\
\text { pada halaman utama }\end{array}$ & Tampil halaman tambah POI & Berhasil \\
\hline & \multirow{2}{*}{ Menekan tombol Pilih File } & Tampil popup untuk memilih file & Berhasil \\
\hline & & Tampil gambar yang telah diunggah & Berhasil \\
\hline & \multirow{2}{*}{ Menekan tombol TAMBAH } & $\begin{array}{l}\text { Tampil peringatan saat data salah dan tidak } \\
\text { lengkap }\end{array}$ & Berhasil \\
\hline & & $\begin{array}{l}\text { Tampil notifikasi berhasil tambah POI ketika } \\
\text { masukan lengkap dan benar }\end{array}$ & Berhasil \\
\hline & Menekan tombol KEMBALI & Tampil halaman utama aplikasi & Berhasil \\
\hline $\begin{array}{l}\text { Lihat Detail } \\
\text { POI }\end{array}$ & $\begin{array}{l}\text { Menekan tombol LIHAT pada } \\
\text { kolom Operasi tabel daftar } \\
\text { POI halaman utama }\end{array}$ & $\begin{array}{l}\text { Tampil halaman detail informasi hotel yang } \\
\text { dipilih }\end{array}$ & Berhasil \\
\hline \multirow{6}{*}{ Ubah POI } & $\begin{array}{l}\text { Menekan tombol UBAH pada } \\
\text { halaman detail POI }\end{array}$ & $\begin{array}{l}\text { Tampil halaman ubah POI yang terisi data POI } \\
\text { yang dipilih }\end{array}$ & Berhasil \\
\hline & \multirow{2}{*}{ Menekan tombol Pilih File } & Tampil popup untuk memilih file & Berhasil \\
\hline & & Tampil gambar yang telah diunggah & Berhasil \\
\hline & \multirow{2}{*}{ Menekan tombol SIMPAN } & $\begin{array}{l}\text { Tampil peringatan saat data salah dan tidak } \\
\text { lengkap }\end{array}$ & Berhasil \\
\hline & & $\begin{array}{l}\text { Tampil notifikasi berhasil ubah POI ketika } \\
\text { masukan lengkap dan benar }\end{array}$ & Berhasil \\
\hline & Menekan tombol BATAL & Tampil halaman utama aplikasi & Berhasil \\
\hline \multirow{3}{*}{ Hapus POI } & $\begin{array}{l}\text { Menekan tombol HAPUS } \\
\text { pada kolom Operasi tabel } \\
\text { daftar POI halaman utama }\end{array}$ & $\begin{array}{l}\text { Tampil pesan konfirmasi hapus data hotel yang } \\
\text { dipilih }\end{array}$ & Berhasil \\
\hline & Menekan tombol OKE & $\begin{array}{l}\text { Tampil notifikasi berhasil hapus data dan POI } \\
\text { terhapus }\end{array}$ & Berhasil \\
\hline & Menekan tombol BATAL & Kembali ke halaman utama aplikasi & Berhasil \\
\hline \multirow{4}{*}{$\begin{array}{l}\text { Tambah } \\
\text { Admin }\end{array}$} & $\begin{array}{l}\text { Menekan menu Tambah } \\
\text { Admin pada halaman utama }\end{array}$ & Tampil halaman tambah admin & Berhasil \\
\hline & \multirow{2}{*}{ Menekan tombol TAMBAH } & $\begin{array}{l}\text { Tampil peringatan saat data salah dan tidak } \\
\text { lengkap }\end{array}$ & Berhasil \\
\hline & & $\begin{array}{l}\text { Tampil notifikasi berhasil tambah admin ketika } \\
\text { masukan lengkap dan benar }\end{array}$ & Berhasil \\
\hline & Menekan tombol BATAL & Tampil halaman utama aplikasi & Berhasil \\
\hline $\begin{array}{l}\text { Profil } \\
\text { Lengkap } \\
\text { Admin }\end{array}$ & $\begin{array}{l}\text { Memilih menu Profil Lengkap } \\
\text { pada menu dropdown admin }\end{array}$ & Tampil halaman informasi profil lengkap admin & Berhasil \\
\hline \multirow{4}{*}{$\begin{array}{l}\text { Ubah Data } \\
\text { Admin }\end{array}$} & $\begin{array}{l}\text { Menekan tombol UBAH pada } \\
\text { halaman profil lengkap admin }\end{array}$ & $\begin{array}{l}\text { Tampil form ubah data admin yang telah terisi } \\
\text { oleh data admin yang masuk }\end{array}$ & Berhasil \\
\hline & Menekan tombol KEMBALI & Tampil halaman utama aplikasi & Berhasil \\
\hline & \multirow{2}{*}{ Menekan tombol SIMPAN } & $\begin{array}{l}\text { Tampil peringatan saat data salah dan tidak } \\
\text { lengkap }\end{array}$ & Berhasil \\
\hline & & $\begin{array}{l}\text { Tampil notifikasi berhasil ubah data admin ketika } \\
\text { masukan lengkap dan benar }\end{array}$ & Berhasil \\
\hline Logout & $\begin{array}{l}\text { Memilih menu Logout pada } \\
\text { menu dropdown admin }\end{array}$ & Tampil halaman login & Berhasil \\
\hline \multirow[t]{2}{*}{ Publish } & $\begin{array}{l}\text { Memilih menu Bintang } 1 \text { pada } \\
\text { menu dropdown Publish }\end{array}$ & Tampil halaman data XML bintang 1 & Berhasil \\
\hline & Menekan tombol UPDATE & Tampil isi file bintang1.xml yang baru & Berhasil \\
\hline
\end{tabular}




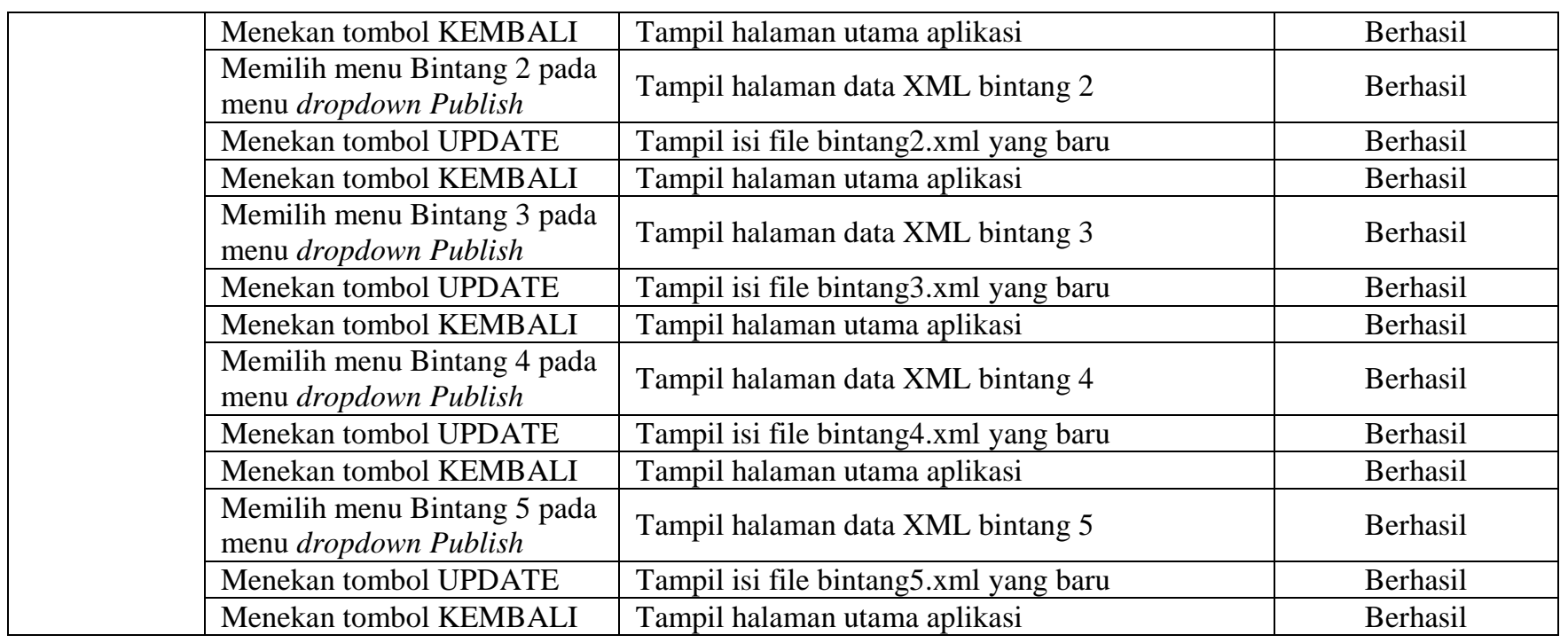

Tabel 2 Tabel pengujian black box channel SMARTEL

\begin{tabular}{|c|c|c|c|}
\hline $\begin{array}{c}\text { Nama } \\
\text { Pengujian }\end{array}$ & Bentuk Pengujian & Hasil yang Diharapkan & Hasil Pengujian \\
\hline \multirow{4}{*}{$\begin{array}{l}\text { Tampilan } \\
\text { Utama }\end{array}$} & \multirow{4}{*}{$\begin{array}{l}\text { Menjalankan Junaio dan } \\
\text { mengakses channel SMARTEL }\end{array}$} & Menampilkan tampilan AR hotel bintang 1 & Berhasil \\
\hline & & Tampil menu tombol 1-5 & Berhasil \\
\hline & & Tampil tombol info & Berhasil \\
\hline & & Tampil radar penunjuk lokasi hotel & Berhasil \\
\hline $\begin{array}{l}\text { Info } \\
\text { Channel }\end{array}$ & Menekan tombol info & $\begin{array}{l}\text { Muncul popup informasi seputarchannel } \\
\text { SMARTEL }\end{array}$ & Berhasil \\
\hline \multirow{5}{*}{$\begin{array}{l}\text { Pindah } \\
\text { Channel } \\
\text { Hotel }\end{array}$} & Menekan tombol 1 & $\begin{array}{l}\text { Muncul POI hotel bintang } 1 \text { dan jarak dari } \\
\text { lokasi user }\end{array}$ & Berhasil \\
\hline & Menekan tombol 2 & $\begin{array}{l}\text { Muncul POI hotel bintang } 2 \text { dan jarak dari } \\
\text { lokasi user }\end{array}$ & Berhasil \\
\hline & Menekan tombol 3 & $\begin{array}{l}\text { Muncul POI hotel bintang } 3 \text { dan jarak dari } \\
\text { lokasi user }\end{array}$ & Berhasil \\
\hline & Menekan tombol 4 & $\begin{array}{l}\text { Muncul POI hotel bintang } 4 \text { dan jarak dari } \\
\text { lokasi user }\end{array}$ & Berhasil \\
\hline & Menekan tombol 5 & $\begin{array}{l}\text { Muncul POI hotel bintang } 5 \text { dan jarak dari } \\
\text { lokasi user }\end{array}$ & Berhasil \\
\hline $\begin{array}{l}\text { POI } \\
\text { Location } \\
\text { Range }\end{array}$ & $\begin{array}{l}\text { Menekan radar dan mengatur } \\
\text { jarak cakupan POI }\end{array}$ & $\begin{array}{l}\text { Menampilkan POI sesuai jarak yang telah } \\
\text { diatur }\end{array}$ & Berhasil \\
\hline \multirow{4}{*}{ Detail POI } & \multirow{4}{*}{$\begin{array}{l}\text { Menekan salah satu POI yang } \\
\text { muncul }\end{array}$} & Tampil halaman deskripsi detail POI & Berhasil \\
\hline & & Tampil tombol Foto Hotel & Berhasil \\
\hline & & Tampil tombol Website & Berhasil \\
\hline & & Tampil tombol Petunjuk Arah & Berhasil \\
\hline Foto Hotel & Menekan tombol Foto Hotel & Tampil foto hotel pada browser Junaio & Berhasil \\
\hline Website & Menekan tombol Website & $\begin{array}{l}\text { Halaman web hotel terbuka pada browser } \\
\text { Junaio }\end{array}$ & Berhasil \\
\hline Navigasi & Menekan tombol Petunjuk Arah & $\begin{array}{l}\text { Tampil peta dan navigasi dari posisi pengguna } \\
\text { berada ke koordinat POI }\end{array}$ & Berhasil \\
\hline
\end{tabular}

